\title{
Nursery ground, age structure and abundance of juvenile squat lobster Pleuroncodes monodon on the continental shelf off central Chile
}

\author{
Rubén Roa ${ }^{1}$, Victor A. Gallardo ${ }^{2,3}$, Billy Ernst ${ }^{3}$, Mario Baltazar ${ }^{3}$, Juan I. Cañete ${ }^{3}$, \\ Sandro Enríquez-Brionnes ${ }^{3}$
}

\author{
${ }^{1}$ Instituto de Fomento Pesquero, Sede Zonal V-IX Regiones, Casilla 347, Talcahuano, Chile \\ ${ }^{2}$ Centro EULA, Universidad de Concepción, Casilla 156-C, Concepción, Chile \\ ${ }^{3}$ Departamento de Oceanografía, Universidad de Concepción, Casilla 2407-10, Concepción, Chile
}

\begin{abstract}
Newly settled individuals and juveniles of several benthic decapod crustaceans spend their first months or years in nursery habitats different from those of the adult population. It was unknown if this was the case for the squat lobster Pleuroncodes monodon, an exploited crustacean which inhabits the continental shelf off central Chile, and of which 2 adult populations exist, the larger Achira $\left(35^{\circ} 10^{\prime} \mathrm{S}\right.$ to $\left.36^{\circ} 15^{\prime} \mathrm{S}\right)$ and the smaller Biobio $\left(36^{\circ} 35^{\prime} \mathrm{S}\right.$ to $\left.36^{\circ} 50^{\prime} \mathrm{S}\right)$. We report here the presence of a large nursery area of the species, connecting both adult populations; the habitat is dominated by extensive sulphide microbial communities which fluorish at very low oxygen concentrations. We inferred the existence of northerly and southerly migration routes from the nursery ground to the adult populations, with juvenile year classes migrating as they advance through age classes. The juvenile population was composed of 2 year classes: $0 \mathrm{yr}$ old (newly settled individuals) and $1 \mathrm{yr}$ old juveniles; thus juveniles seemed to spend their first year of life in the nursery area. Total abundance was estimated as $3290 \times 10^{6}$ individuals (asymmetric $95 \%$ confidence interval: 2153 to $7039 \times 10^{6}$ ), although the above figure is a lower bound because the sampling did not cover the whole nursery area. We hypothesize that the Biobio adult population is not self-sustaining, but depends on a surplus production of juveniles from the Achira population.
\end{abstract}

KEY WORDS: Squat lobster · Nursery grounds · Population biology $\cdot$ Benthic environment $\cdot$ Continental shelf · Central Chile

\section{INTRODUCTION}

Recruitment strength is a major factor in determining population dynamics of many fish and invertebrate stocks in marine environments. The interplay between high fecundity and variable mortality of the pelagic larval phase accounts for a large part of population fluctuations in abundance and structure (Fogarty et al. 1991, Koslow 1992, Doharty \& Fowler 1994). In some benthic crustacean populations, including penaeid shrimps and lobsters, juveniles spend their first months or years of life in nursery areas different from those of the adult population (García \& Le Reste 1981, Phillips 1986, Bishop \& Kahn 1991, Wahle \& Steneck 1991, Pollock 1993, Rogers et al. 1993, Watson \& Turnbull 1993).
Consequently, a necessary step towards understanding and monitoring recruitment in benthic crustaceans is a study on the existence and location of nursery grounds.

The squat lobster Pleuroncodes monodon is a small galatheid decapod found on the continental shelf off central Chile and harvested by a trawling fleet. There are 2 large adult populations, the northern Achira and the southern Biobio (Bahamonde et al. 1986, Roa \& Bahamonde 1993) (Fig. 1), which together support an annual catch of about $4000 \mathrm{t}$. Recently, we reported the existence of juvenile aggregations south of the Achira population, although the spatial scale of our sampling was too limited to identify the region as a nursery ground (Gallardo et al. 1994). However, those results 


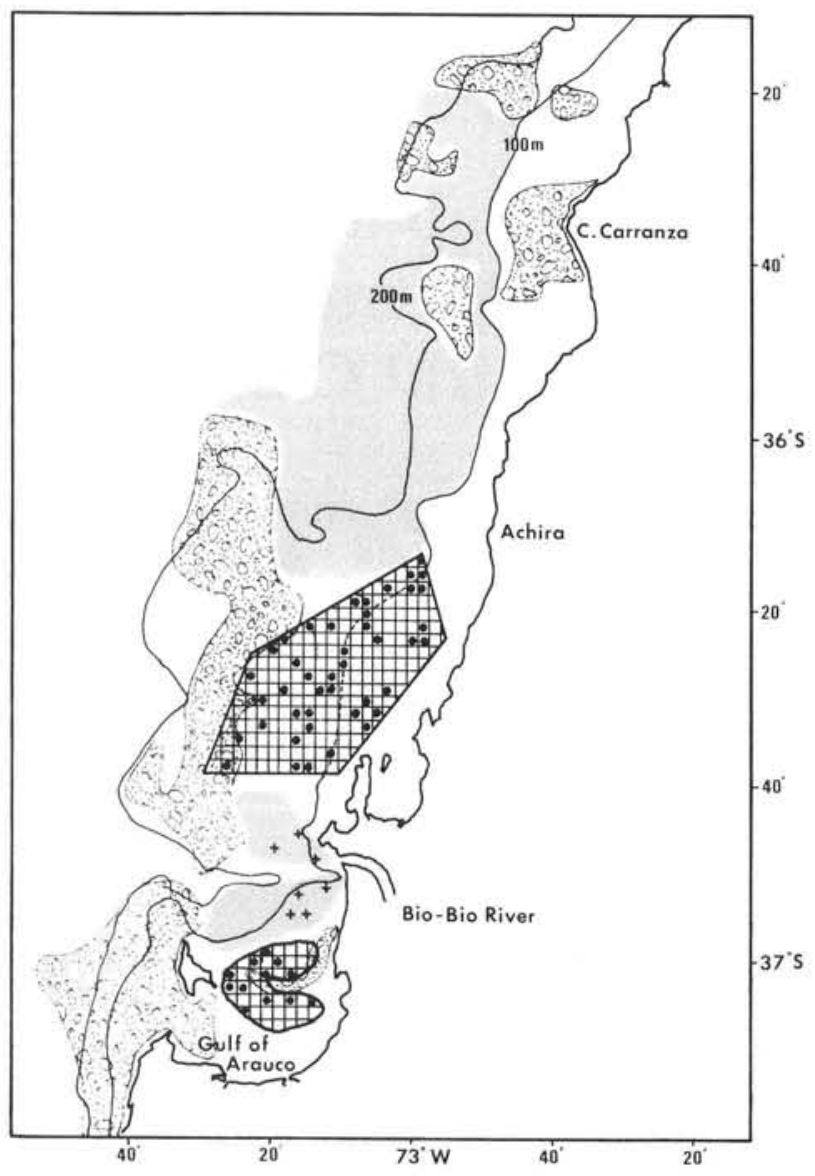

Fig. 1. Sampling region for juvenile squat lobsters Pleuroncodes monodon. - inside gridded area: quadrats randomly chosen for sampling; + : hauls in the exploration area; cobblelike areas: hard untrawlable bottoms; shaded areas show the Achira (north) and Biobio populations

suggested that nursery grounds may exist south of the adult populations, a hypothesis further supported by the fact that, in the Achira population, individuals show a clear latitudinal separation of year classes: younger individuals populate the southern areas (Roa \& Bahamonde 1993).

The hypothetical nursery areas are located on a region of intense seasonal upwelling (Arcos \& Wilson 1984), with very low dissolved oxygen concentrations, and whose bottom is covered by large microbial communities (Thioploca spp.; Gallardo 1977). A trophic relationship between the squat lobster and Thioploca spp, has been suggested (Gallardo 1977). Thioploca spp. bottoms may also serve as a refuge from predation, given that juvenile squat lobster is one of the main prey items of the hake Merluccius gayi (Arancibia \& Meléndez 1987), the most abundant demersal fish off central Chile. However, a small-scale spatial association between Thioploca spp. mats and juvenile squat lobster has not been demonstrated.
The age structure of the juvenile fraction of the squat lobster population is rather unclear. Roa (1993) used 5 research surveys done between 1982 and 1991 to analyse the age structure of the adult Achira population. However, the author lacked information on juvenile year classes, due to the fishing gear used and locations sampled in those surveys. The purpose of the present study was to analyse data from a research survey especially designed to cover the likely grounds of the juvenile fraction of the squat lobster population. We describe part of a large nursery area, provide estimates of abundance, disclose the age structure of early benthic and adult life, and describe the association of the squat lobster with oceanographic features and the presence of Thioploca spp. mats.

\section{MATERIALS AND METHODS}

Field and laboratory methods. Previous results from 1991 and January and March 1992 (Gallardo et al. 1994) showed that the main period of benthic settlement was April. Therefore, the survey for juveniles was performed in April 1993. The sampling was made onboard the $17 \mathrm{~m}$ RV 'Kay-Kay', using an Agassiz trawl (1 $\mathrm{m}$ width at the mouth) towed at 2 knots and whose mesh size ( $4 \mathrm{~mm}$ at the codend) was adopted to retain even the smallest individuals.

The likely juvenile grounds were inferred from the distribution of larger individuals, referred to as adults for convenience. Adults inhabit 2 populations separated by ca $45 \mathrm{~km}$, the northern Achira and the southern Biobio populations (Fig. 1), of which the former is 4 to 5 times larger in terms of numeric abundance (Roa 1994). In 1991, the Achira population showed a clear spatial age structure, with smaller (i.e. younger) individuals inhabiting the southern end of the adult population, and larger (i.e. older) ones populating the northern end (Roa \& Bahamonde 1993). Consequently, we inferred that the Achira population was fed with juveniles from the south, and defined a survey area between $36^{\circ} 10^{\prime} \mathrm{S}$ and $36^{\circ} 40^{\prime} \mathrm{S}$ (Fig. 1). The oceanic border of this area was determined on the basis of the presence of hard untrawlable bottoms. The squat lobster has not been found on shallow coastal bottoms. Using this information we determined a survey area of $1950 \mathrm{~km}^{2}$ (Area 1) for the juvenile grounds of the Achira population (Fig. 1). A second smaller adult population, the Biobio population, inhabits the region surrounding a submarine canyon off the Biobio River mouth (Fig. 1). We assumed that this population would also be fed with juveniles from the south, and then determined a second survey area of $341 \mathrm{~km}^{2}$ (Area 2) inside the Gulf of Arauco (Fig. 1). 
Both survey areas were gridded into $10 \mathrm{~km}^{2}$ quadrats, and a total of 44 quadrats were randomly chosen in Area 1 and 12 in Area 2. One haul was made in each quadrat, assuming that abundance was homogeneous within each one. When the sampling of both areas was finished, 7 additional hauls (locations chosen haphazardly) were made to obtain information on the region surrounding the submarine canyon (Fig. 1). Initial and final positions of each haul were recorded with a Global Positioning System (GPS, Trimble Trans Pack I, $\pm 30 \mathrm{~m}$ measurement error). On each haul, the total catch of lobsters was fixed with $10 \%$ formaldehyde in seawater and the presence or absence of Thioploca spp. filaments was recorded. Together with trawling, bottom water samples were taken in some quadrats (22 in Area 1, 5 in Area 2, and 3 in the exploration area). Water temperature was recorded in situ. A sample of water was immediately fixed for Winkler titration, and the rest of the water was stored for salinity measurement.

For each haul the total catch in numbers was measured. Individuals were separated according to sex (visual observation of ovigerous setae), and carapace length $(\mathrm{CL}$, from the eye socket dorsally along a line parallel to the midline to the posterior edge of the carapace) was measured to the nearest $0.1 \mathrm{~mm}$. When hauls yielded very abundant catches a subsample of about 250 individuals was randomly taken to determine sex and CL. Some individuals, classified as undetermined, could not be sexed with certainty due to small size.

Estimation of total abundance. Total abundance $(\hat{P})$ was determined using the swept area method, which is based on the assumption that catch per unit of effort (CPUE) is linearly proportional to population density (population abundance/area, $P / A$ ), with the coefficient of proportionality being the catchability coefficient $(q)$ (Ricker 1975; see also Ralston \& Tagami 1992 and Roa \& Bahamonde 1993 for specific applications). The expression for total abundance is

$$
\hat{P}=\frac{A}{q} \times \overline{\left(\frac{C}{a}\right)}=\frac{A}{q} \times \overline{\mathrm{CPUE}}
$$

where $a$ is the area swept by the trawl on any haul. In this work, we express catch $(C)$, and therefore abundance, as number of individuals. To delimit $A$, the coastal border was drawn at mid distance between hauls with absence and presence of squat lobsters; the oceanic border was drawn following the natural perimeter of hard untrawlable bottoms, and the northern and southern borders were drawn as the smallest distance between extreme hauls (Fig. 2). The area enclosed by the perimeter was measured with a digital planimeter (LASICO 1280 Digitizer 42-C).
Effort corresponded to the area swept by the trawl on each haul, which was calculated using initial and final positions recorded by the GPS and Pythagoras' theorem corrected for latitudinal position (Sparre et al. 1989):

$$
a=(1852 \times 60) \sqrt{\left(L T_{1}-L T_{2}\right)^{2}+\left(L N_{1}-L N_{2}\right)^{2} \cos ^{2}\left(\frac{L T_{1}-L T_{2}}{2}\right)}
$$

where $L T_{1}$ and $L T_{2}$ are initial and final latitude, $L N_{1}$ and $L N_{2}$ are initial and final longitude, and the factor $1852 \times 60$ converts from degrees to meters. This quantity corresponded to distance travelled but also to area swept because the trawl mouth had a width of $1 \mathrm{~m}$.

In the absence of specific information, the catchability coefficient $(q)$ was set equal to 1 . This value means that all individuals within the path swept by the trawl (and only those individuals) were caught by the trawl. This assumption can be supported by the fact that no herding effect, which causes the capture of individuals from outside the swept area $(q>1)$, has been described for benthic crustaceans. In fishes, the herding effect occurs when the bridles and otter doors of the approaching trawl herd fish into the path swept by the trawl, overestimating local density (e.g. see Krieger 1993). Also, escape of individuals from inside the swept path $(q<1)$ seems unlikely with the trawl approaching at velocities of 2 knots (ca $1.0 \mathrm{~m} \mathrm{~s}^{-1}$ ) and bottom currents on the order of a few $\mathrm{cm} \mathrm{s}^{-1}$ (Marcus Sobarzo, Centro EULA, pers. comm.), although we lack information on natatory capabilities of small squat lobsters.

To estimate mean CPUE in Eq. (1), we first analysed the distribution of CPUE values. We expected that CPUE values would distribute log-normally, as is usual in bottom trawling surveys (Pennington 1986, McConnaughey \& Conquest 1993), and they did (Fig. 3, and see 'Results'). Thus, mean CPUE was estimated as the maximum-likelihood Finney-Sichel estimator (McConnaughey \& Conquest 1993):

$$
F S=\exp (y) G(r)
$$

where $y$ is the arithmetic mean of the variable (CPUE) expressed as natural logarithm [ln(CPUE)], and $G(r)$ is a function of the variance of $\ln (\mathrm{CPUE})$ of the form:

$$
G(r)=1+\frac{(\mathrm{n}-1) r}{\mathrm{n}}+\frac{(\mathrm{n}-1)^{3} r^{2}}{2 ! \mathrm{n}^{2}(\mathrm{n}+1)}+\frac{(\mathrm{n}-1)^{5} r^{3}}{3 ! \mathrm{n}^{3}(\mathrm{n}+1)(\mathrm{n}+3)}+\cdots
$$

where $\mathrm{n}$ is the number of hauls (all with positive catches) and $r=s^{2} / 2$, where $s^{2}$ is the variance of $\ln$ (CPUE). $G(r)$ is an infinite series, but we computed the Finney-Sichel estimator by using the first through the seventh terms of the series, the seventh being $1 / 100000$ of the first term. The variance of the FinneySichel estimator is given by (Pennington 1986): 

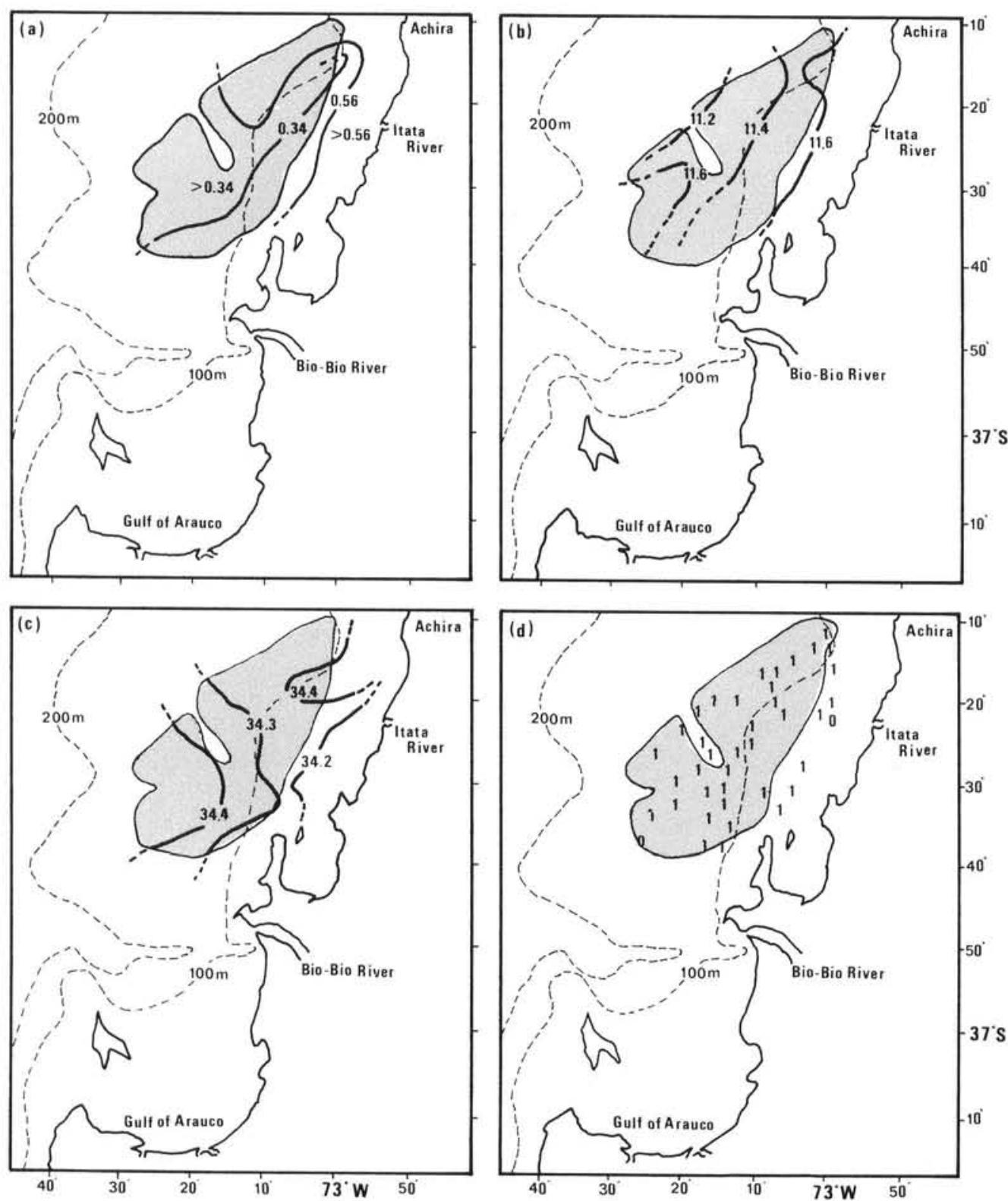

Fig. 2. Delimitation of the nursery area (central shaded area) and its habitat characteristics. (a) Oxylines $\left(\mathrm{mg} \mathrm{l}^{-1}\right)$; (b) isotherms $\left({ }^{\circ} \mathrm{C}\right)$; (c) isohalines; (d) presence (1) and absence $(0)$ of Thioploca spp.

$$
\operatorname{var}(F S)=\exp (2 y)\left[G^{2}-G \frac{(\mathrm{n}-2) 2 r}{(\mathrm{n}-1)}\right]
$$

where hauls with positive catches only are considered. A confidence interval for the abundance estimator (Eq. 1) was computed by assuming that the population area and the mean area swept were measured without error, so that $A / q$ is a constant, and by noting that the standard error of the product of a constant and an estimate with error is the product of the constant and the standard error of the estimate (Seber 1982). Hence, the confidence interval of the abundance estimator would be given by the product of $A / q$ and the confidence limits of the Finney-Sichel estimator, which are asymmet- ric by virtue of the asymmetry of the log-normal distribution. Those limits are computed as (McConnaughey \& Conquest 1993):

$$
\begin{aligned}
U_{1-\alpha} & =\exp \left(y+r+H_{1-\alpha} \sqrt{\frac{2 r}{\mathrm{n}-1}}\right) \\
L_{\alpha} & =\exp \left(y+r+H_{\alpha} \sqrt{\frac{2 r}{\mathrm{n}-1}}\right)
\end{aligned}
$$

where $U$ and $L$ stand for upper and lower limits, and the $H$ statistics (different for each limit) depend on the number of degrees of freedom and the variance of In(CPUE), and are tabulated in Land (1975). Our particular combination of degrees of freedom and vari- 
ance was not found in Land's (1975) tables, so a cubic interpolation was computed, as suggested by Land (1975). A measure of percent relative error in abundance estimation (RE) was given by REL $=100(P-L) / P$ and REU $=$ $100(U-P) / P$ for lower and upper limits respectively.

Analysis of population structure. An exploratory plot showed that male and female size distributions, and those of the undetermined (usually very small) individuals, were very similar (Fig. 4a). Consequently, size distribution data were pooled for further analysis. The global histogram was disclosed into year classes using the statistical-numerical algorithm MIX (Macdonald \& Pitcher 1979) with criteria according to Roa (1993).

\section{RESULTS}

\section{Abundance and delimitation of a nursery ground}

There were no catches of juvenile squat lobsters in the 12 hauls of Area 2; however, the catches in Area 1 and in the exploration area were highly successful (Table $1 ; 29$ successful hauls out of 44). Unsuccessful hauls at the coastal border in Area 1, together with the natural perimeter of the hard untrawlable bottoms on the oceanic border and the northern and southern hauls, were used to delimit the nursery ground (Fig. 2). The northern and southern extreme hauls yielded high abundances, and thus those borders drawn did not enclose the whole nursery area. CPUE values showed a typical log-normal distribution, with many values concentrated on the smaller classes and a tail towards greater classes (Fig. 3a). Logarithmic tranformation of the CPUE values yielded a more symmetrical (normal) distribution, although low sample size ( 29 successful hauls) precluded a completely clear picture (Fig. 3 b). The relative error in abundance estimation was rather high for both limits (Table 1), a consequence of low sample effort.

\section{Population structure}

The size structure of juvenile squat lobster in the nursery ground showed the presence of 2 year classes for both sexes, with clear normal distributions for both (Fig. 4a). The sexually undetermined individuals belonged to the normal distribution with the smallest mean size (smallest year class). When estimating the
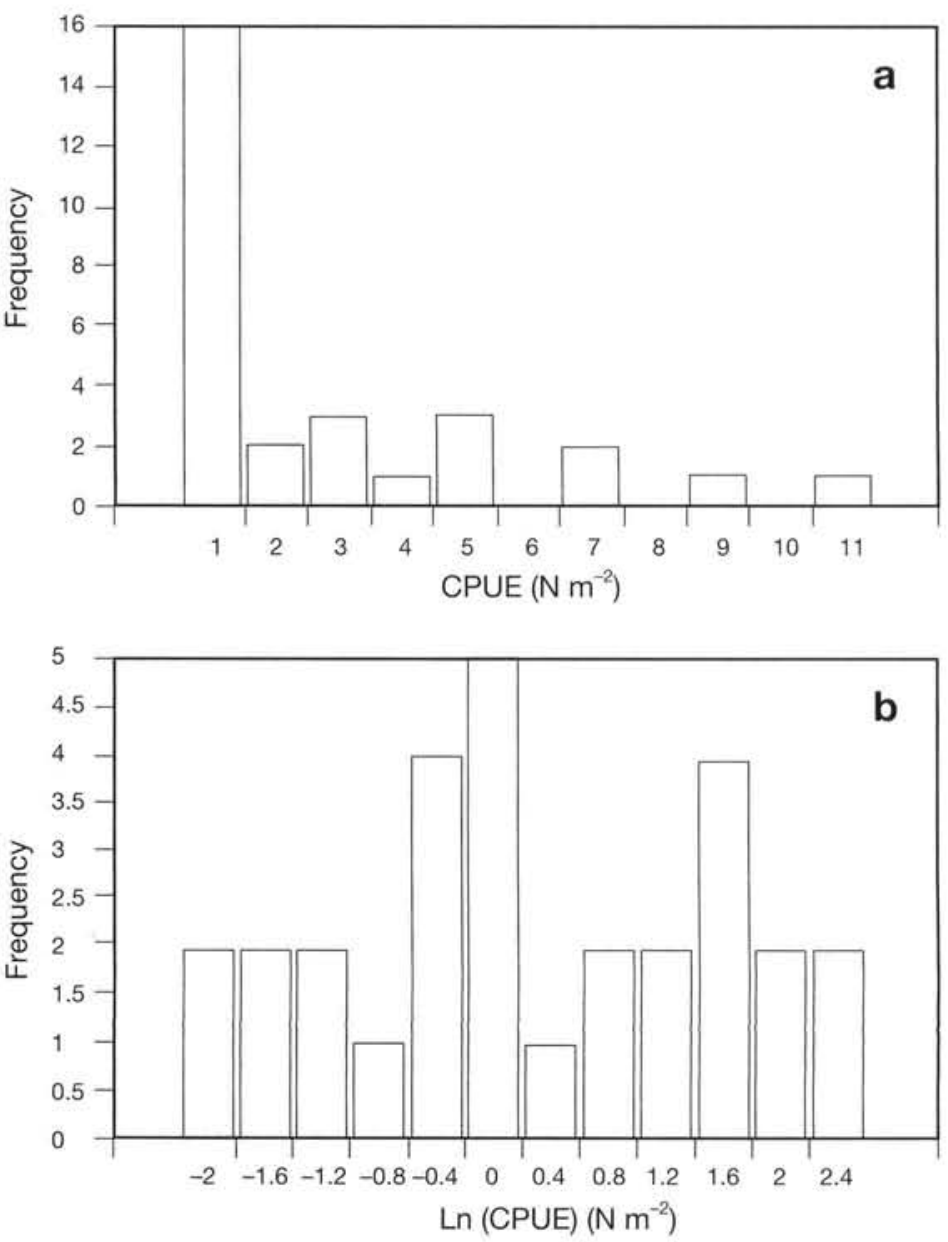

Fig. 3. Pleuroncodes monodon. Distribution of catch per unit of effort (CPUE) values. (a) Untransformed values; (b) natural logarithm of CPUE

parameters of the distribution mixture (data pooled), we obtained mean sizes of 6.5 and $12.5 \mathrm{~mm} \mathrm{CL}$, with a highly dominant representation, in terms of numeric abundance, of the smallest year class (Fig. 4b, Table 2).

Table 1. Pleuroncodes monodon. Size of area, lobster density (SD), and abundance on the nursery ground. Only successful hauls are considered

\begin{tabular}{|lcc|}
\hline & Area 1 & Exploration area \\
\hline Degrees of freedom & 28 & 6 \\
Area $\left(\mathrm{km}^{2}\right)$ & 1376 & - \\
Density $\left(\right.$ ind. $\left.\mathrm{m}^{-2}\right)$ & $2.39(1.19)$ & $0.74(0.54)$ \\
Abundance $\left(\times 10^{6}\right.$ ind.) & 3290 & - \\
Lower $2.5 \%$ limit & 2153 & - \\
Relative error & 34.5 & - \\
Upper $97.5 \%$ limit & 7039 & - \\
Relative error & 114.0 & - \\
\hline
\end{tabular}



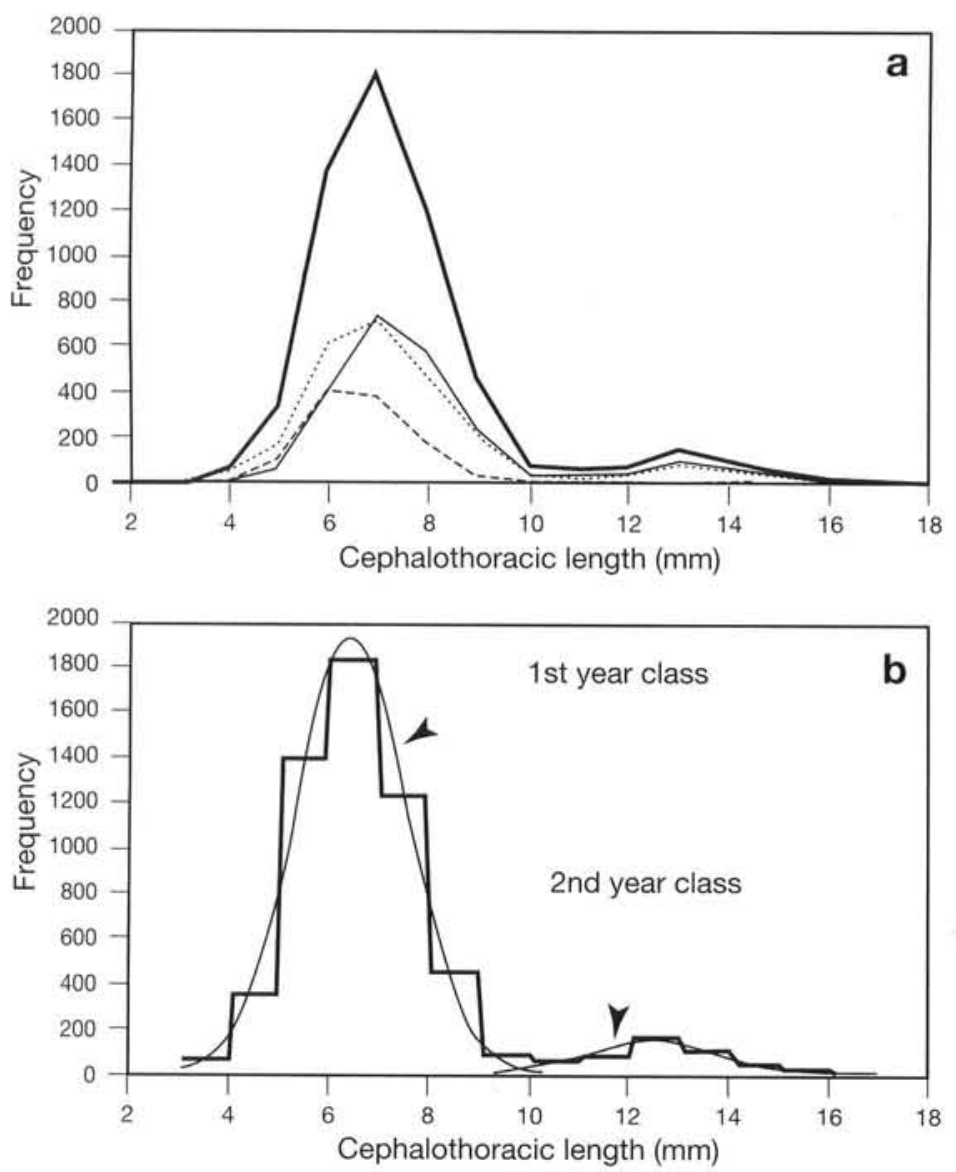

Fig. 4. Pleuroncodes monodon. Size and age structure of juvenile squat lobsters in the nursery ground. (a) Total sample (heavy solid line, $\mathrm{n}=$ 5818), males (solid), females (dotted), undetermined (dashed). (b) Raw data (heavy solid line), and fitted year classes (solid smooth lines)

Table 2. Pleuroncodes monodon. Parameters of the fitted distribution mixture for the population structure in the nursery ground. Sample size $=4733$. Standard errors in parentheses

\begin{tabular}{|lcc|}
\hline Statistic & \multicolumn{2}{c|}{ Year class } \\
& 1993 & 1992 \\
\hline Age & 0 & 1 \\
Mean size (CL, mm) & $6.51(0.01)$ & $12.51(0.08)$ \\
Standard deviation (mm) & $1.11(0.01)$ & $1.39(0.06)$ \\
Proportion & $0.917(0.004)$ & $0.083(0.004)$ \\
\hline
\end{tabular}

The mean size of the megalopae sampled in the same period was $4.5 \mathrm{~mm}$ CL (authors' unpubl. results), thus the first year class, of $6.5 \mathrm{~mm} \mathrm{CL}$, corresponded to just-settled individuals, of $0 \mathrm{yr}$ old. Given the absence of another year class between the first and second ones, the second year class corresponded to individuals settled the previous year, or 1 yr old. We will refer to the 1992 and 1993 year classes for individuals of 1 and 0 yr old respectively.

\section{Oceanographic environment and Thioploca spp.}

Charts of oceanographic features of the bottom water and the presence/absence of Thioploca spp. in Area 1 are shown on Fig. 2. Oxygen concentrations, temperature, and salinity were typical of the Peru-Chile Subsurface Countercurrent (Ahumada et al. 1983). The nursery area is located on a bottom almost completely covered with Thioploca spp., demonstrating a close small-scale spatial association between juvenile squat lobsters and bacterial mats.

In Area 2, the oceanographic environment was characterized by a mean depth, oxygen concentration, salinity, and temperature of $47.2(\mathrm{SD}=18.8) \mathrm{m}, 0.712(0.248) \mathrm{mg} \mathrm{l}^{-1}$, $34.355(0.055) \%$, and $11.5(0.1){ }^{\circ} \mathrm{C}$, respectively. In all 12 stations we recorded the presence of Thioploca spp. filaments. Consequently, both Areas 1 and 2 have similar oceanographic and biological conditions.

\section{DISCUSSION}

The squat lobster population in central Chile has a spatially structured age composition. Newly settled individuals spend their first year of life in a large nursery ground, located between the Achira and Biobio adult populations, virtually connecting them. In the northern Achira population, adult year classes ( $2 \mathrm{yr}$ and older) show a latitudinal transition from younger year classes in the south and older ones in the north (Roa \& Bahamonde 1993). Therefore, there exists a continuum from south in the nursery area to north in the Achira population, with a northern migration route as year classes advance through age classes. On the other hand, the presence of newly settled individuals in the exploration zone and their absence south of the Biobio adult population indicates that a similar southern migration route exists, with newly settled individuals from the nursery ground supporting the Biobio population. In other words, a common nursery ground provides recruits for both the larger Achira and the smaller Biobio populations.

The existence of a common nursery area for both spawning stocks raises the question of the relative contribution of the adult populations to the juvenile stock. The larvae hatch in a period of the year (spring-early summer; Palma \& Arana 1990) when the benthic environment is dominated by the Peru-Chile Subsurface Countercurrent, which, despite local and transient 
variations, has a southerly flow (Brockmann et al. 1980, Huyer et al. 1991). Consequently, larvae from the Biobio spawning stock would be advected south, especially early stages (zoeas). However, we did not find newly settled and juvenile individuals south of the Biobio population. Oceanographic and biological conditions were similar to those in Area 1, south of the Achira population. Therefore, it might be that a significant fraction of the larvae from the Biobio spawning stock is lost from the population area, and that this population depends on juveniles exported from the Achira spawning stock.

The situation where juvenile crustaceans spend their first months or years of life in nursery areas and then migrate into adult populations has been reported for penaeid stocks (Garcia \& Le Reste 1981) and lobsters (Phillips 1990, Wahle \& Steneck 1991). Nursery areas in penaeids are normally estuaries (García \& Le Reste 1981), although seagrass habitats (Watson \& Turnbull 1993) and shallow mudflats (Bishop \& Kahn 1991) have also been reported as nursery habitats. For the Australian rock lobster Panulirus cygnus, nursery grounds are inshore limestone reefs (Phillips 1990) while for the American lobster Homarus americanus in Maine it is cobble substratum (Wahle \& Steneck 1991). The squat-lobster case provides another kind of nursery habitat which is a reflection of the local features of the central Chile continental shelf: the extensive microbial communities which flourish under conditions of very low oxygen concentrations. In every case, those different nursery habitats in penaeid shrimps, rock lobster, American lobster, and squat lobster may share the property of providing food and/or refuge from the strong predation pressure experienced by juveniles (Bishop \& Kahn 1991, Wahle 1992). Juvenile squat lobsters are one of the main prey items of the hake Merluccius gayi, the dominant demersal fish off central Chile. Our results, then, lend credence to Gallardo's (1977) hypothesis that there exists a strong association between the microbial communities and the stock of the squat lobster. Nevertheless, whether the environment of the microbial communities is advantageous for juvenile lobsters and/or does not differ in that respect with other habitats of the region remains unknown.

Oceanographical conditions of the bottom waters correspond to those of the Peru-Chile Subsurface Countercurrent, characterized by very low oxygen concentrations (Fig. 2a). Abundance and other population variables (size-age structure and sex proportion) were not correlated with oceanographic conditions on a local basis (pairwise linear correlations, p > 0.05). Therefore it seems that the oceanographic conditions contribute to the environment in which the juvenile squat lobster spends its benthic life, but do not cause local variations in population variables. On the other hand, oxygen profiles (Fig. 2a) indicate that, at the time of our survey, the oxygen-poor Peru-Chile Countercurrent was reaching shallow depths. However, off central Chile, the border between this poleward subsurface water mass and the surface equatorward oxygen-rich Subantarctic water is seasonally dynamic, being shallowest during spring-summer upwelling and deepest during autumn-winter upwelling relaxation (Fonseca 1986). It is this seasonal variation in oceanographic conditions, in particular, that may affect bathymetric distribution of the whole juvenile population, as suggested for adult squat lobster by Bahamonde et al. (1986).

The age structure of the juvenile populations in the nursery ground allows completion of the age structure study done by Roa (1993). In Roa's work juvenile year classes were absent, but mean sizes of adult year classes and the parameters associated with the fitted growth function predicted the existence of 2 juvenile year classes of mean sizes similar to those reported here (age 0: $4.4 \mathrm{~mm}$ CL predicted, 6.5 estimated here; age 1: 11.8 predicted, 12.5 estimated here; average of both sexes). Considering Roa's analysis and results of this study, it can be concluded that the age structure of the squat lobster population is made up of 8 age classes in males, and 9 in females. This can be regarded as the longevity of the species, under current exploitation conditions.

Our estimation of juvenile abundance in the nursery ground can only be considered as preliminary, however. First, the sampling effort (26 successful hauls) was low for a region of $1376 \mathrm{~km}^{2}$, resulting in high relative errors for the estimation. Second, we did not cover the whole nursery area, which leaves an unknown portion of the juvenile population to the north and the south of the assessment area unsampled. Also, the existence of juveniles on the hard untrawlable bottoms to the oceanic border remains unconfirmed. Our estimate of abundance can be considered as a lower limit, in the sense that there are no less than the amount estimated, with the specified degree of certainty. However, our discovery of the nursery ground and the border drawn for it makes it possible to monitor recruitment strength on a yearly basis. An annual series of recruitment indices may serve as a tool in evaluating the relationship, if it exists, between recruitment strength and spawning stock of the squat lobster. The importance of such knowledge has been forcefully stressed by Phillips (1989), despite the costs involved in the construction of time series sufficiently long to attain statistical certainty. On the other hand, without regard to the spawning stock-recruitment strength relationship, a series of recruitment indices remains a useful management tool for predict- 
ing the level of future commercial catches, much in the way that it is currently done for the rock lobster fishery in western Australia (Phillips 1986).

Acknowledgements. We are grateful to Renato Quiñones, Ignacio Payá and Ingo Werhtmann for reading the manuscript and making useful comments and criticisms. Robert McConnaughey kindly provided a copy of Land's (1975) paper. Three anonymous referees made several comments that contributed to clarification of the text. This paper was written on the basis of the final report of the study Reclutamiento Ecológico en el Langostino Colorado. Fase II', funded by the Subsecretariat of Fishing, Ministry of Economy of the Republic of Chile. Soledad Zorzano, of the Subsecretariat, provided the impetus to do this work.

\section{LITERATURE CITED}

Ahumada, R., Rudolph, A., Martínez, V. (1983). Circulation and fertility of water in Concepción Bay, Chile. Estuar. coast. Shelf Sci. 16: 95-105

Arancibia, H., Meléndez, R. (1987). Alimentación de peces concurrentes en la pesquería de Pleuroncodes monodon Milne-Edwards. Investigación pesq. (Chile) 34: 113-128

Arcos, D. F., Wilson, R. E. (1984). Upwelling and the distribution of chlorophyll a within the Bay of Concepción, Chile. Estuar, coast. Shelf Sci. 18: 25-35

Bahamonde, N., Henríquez, G., Zuleta, A., Bustos, H., Bahamonde, R. (1986). Population dynamics and fisheries of squat lobsters, Family Galatheidae, in Chile. Can. Spec. Publ. Fish. Aquat. Sci. 92: 254-268

Bishop, J. M., Kahn, M. H. (1991). Depth as a factor in abundance and size of juvenile penaeid shrimps in the absence of estuaries and marshes. Mar. Biol. 109: 103-114

Brockmann, C., Fahrbach, E., Huyer, A., Smith, R. L. (1980). The poleward undercurrent along the Peru coast: 5 to $15^{\circ}$ S. Deep Sea Res. 27: 847-856

Doharty, P., Fowler, T. (1994). An empirical test of recruitment limitation in a coral reef fish. Science 263: 935-939

Fogarty, M. J., Sissenwine, M. P., Cohen, E. B. (1991). Recruitment variability and the dynamics of exploited marine populations. Trends Ecol. Evol. 6: 241-246

Fonseca, T. R. (1989). An overview of the poleward undercurrent and upwelling along the Chilean coast. In: Nishyba, S. J., Mooers, Ch. N. K., Smith, R. L., Barber, R. T. (eds.) Poleward flows along eastern ocean boundaries. Coastal and estuarine studies 34. Springer-Verlag, New York, p. $177-228$

Gallardo, V. A. (1977). Large benthic microbial communities in sulphide biota under the Peru-Chile subsurface countercurrent, Nature 268: 331-332

Gallardo, V. A., Cañete, J. I., Roa, R., Enríquez-Briones, S., Baltazar, M. (1994). Recruitment of the squat lobster Pleuroncodes monodon on the continental shelf off central Chile. J. Crust. Biol. 14: 665-669

Garcia, S., Le Reste, L. (1981). Life cycles, dynamics, exploitations and managements of coastal penaeid shrimp stocks. FAO Fish. Tech. Pap. 203

Huyer, A., Knoll, M., Paluszkiewicz, T., Smith, R. L. (1991). The Perú undercurrent: a study in variability. Deep Sea Res. 38: s247-s271

Koslow, J. A. (1992). Fecundity and the stock-recruitment relationship. Can. J. Fish. Aquat. Sci. 49: 210-217
Krieger, K. J. (1993). Distribution and abundance of rockfish determined from a submersible and by bottom trawling. Fish. Bull. U.S. 91: 87-96

Land, C. E. (1975). Tables of confidence limits for linear functions of the normal mean and variance. Sel. Tables Math. Stat. 3: 385-419

Macdonald, P. D. M., Pitcher, T. J. (1979). Age-groups from size-frequency data: a versatile and efficient method of analysing distribution mixtures. J. Fish. Res. Bd Can. 36: $987-1001$

McConnaughey, R. A., Conquest, L. L. (1993). Trawl survey estimation using a comparative approach based on lognormal theory. Fish. Bull. U.S. 91: 107-118

Palma, S., Arana, S. (1990). Aspectos reproductivos del langostino colorado (Pleuroncodes monodon) en la zona centro-sur de Chile. Estudios y Documentos Univ. Católica 1/90 (Mimeo), Valparaíso

Pennington, M. (1986). Some statistical techniques for estimating abundance indices from trawl surveys. Fish. Bull. U.S. 84: 519-525

Philips, B. F. (1986). Prediction of commercial catches of the western rock lobster Panulirus cygnus. Can. J. Fish. Aquat. Sci. 43: 2126-2130

Philips, B. F. (1990). Estimating the density and mortality of juvenile western rock lobster (Panulirus cygnus) in nursery reefs. Can. J. Fish. Aquat. Sci, 47: 1330-1338

Pollock, D. E. (1993). Recruitment overfishing and resilience in spiny lobster populations. ICES J. mar. Sci. 50: 9-14

Ralston, S., Tagami, D. T. (1992). An assessment of the exploitable biomass of Heterocarpus laevigatus in the main Hawaiian islands. 1. Trapping surveys, depletion experiment, and length structure. Fish. Bull. U.S. 90: 494-504

Ricker, W. E. (1975). Computation and interpretation of biological statistics of fish populations. Bull. Fish. Res. Bd Can. 191: 1-382

Roa, R. (1993). Annual growth and maturity function of the squat lobster Pleuroncodes monodon in central Chile. Mar. Ecol. Prog. Ser. 97: 157-166

Roa, R. (1994). Análisis metodológico de la pesquería de langostino colorado. Technical Report of the Fisheries Development Institute, Santiago, Chile, p. 1-86

Roa, R., Bahamonde, R. (1993). Growth and expansion of an exploited population of the squat lobster (Pleuroncodes monodon) after 3 years without harvesting. Fish. Res. 18: 305-319

Rogers, B. D., Shaw, R. F., Herke, W. H., Blanchet, R. H. (1993). Recruitment of postlarval and juvenile brown shrimp (Penaeus aztecus Ives) from offshore to estuarine waters of the northwestern Gulf of Mexico. Estuar. coast. Shelf Sci. 36: 377-394

Seber, G. A. F. (1982). The estimation of animal animal abundance and related parameters, 2nd edn. Macmillan, New York

Sparre, P., Ursin, E., Venema, S. C. (1989). Introduction to tropical fish stock assessment. FAO Fish. Tech. Pap. 306/1

Wahle, R. A. (1992). Body-size dependent anti-predator mechanisms of the American lobster. Oikos 65: 52-60

Wahle, R. A., Steneck, R. S. (1991). Recruitment habitats and nursery grounds of the American lobster Homarus americanus - a demographic bottleneck. Mar. Ecol. Prog. Ser. 69: $231-243$

Watson, R. A., Turnbull, C. T. (1993). Migration and growth of two tropical penaeid shrimps within Torres Strait, northern Australia. Fish. Res. 17: 353-368 